\title{
Clinical presentation, management, and short-term outcome of patients with type A acute dissection complicated by mesenteric malperfusion: Observations from the International Registry of Acute Aortic Dissection
}

Marco Di Eusanio, MD, PhD, ${ }^{\mathrm{a}}$ Santi Trimarchi, MD, ${ }^{\mathrm{b}}$ Himanshu J. Patel, MD, ${ }^{\mathrm{c}}$ Stuart Hutchison, MD, FACC, FRCPC, ${ }^{\mathrm{d}}$ Toru Suzuki, MD, PhD,${ }^{\mathrm{e}}$ Mark D. Peterson, MD, PhD, FRCSC, ${ }^{\mathrm{f}}$ Roberto Di Bartolomeo, MD, ${ }^{\mathrm{a}}$ Gianluca Folesani, MD, ${ }^{\mathrm{a}}$ Reed E. Pyeritz, MD, PhD, ${ }^{\mathrm{g}}$ Alan C. Braverman, MD, ${ }^{\mathrm{h}}$ Daniel G. Montgomery, BS, ${ }^{\mathrm{i}}$ Eric M. Isselbacher, MD, ${ }^{\mathrm{j}}$ Christoph A. Nienaber, MD, FACC, FESC, ${ }^{\mathrm{k}}$ Kim A. Eagle, MD, FACC, ${ }^{\mathrm{i}}$ and Rossella Fattori, MD ${ }^{\mathrm{a}}$

Background: Few data exist on clinical/imaging characteristics, management, and outcomes of patients with type A acute dissection and mesenteric malperfusion.

Methods: Patients with type A acute dissection enrolled in the International Registry for Acute Dissection (IRAD) were evaluated to assess differences in clinical features, management, and in-hospital outcomes according to the presence/absence of mesenteric malperfusion. A mortality model was used to identify predictors of in-hospital mortality in patients with mesenteric malperfusion.

Results: Mesenteric malperfusion was detected in 68 (3.7\%) of 1809 patients with type A acute dissection. Patients with mesenteric malperfusion were more likely to be older and to have coma, cerebrovascular accident, spinal cord ischemia, acute renal failure, limb ischemia, and any pulse deficit. They were less likely to undergo surgical/hybrid treatment $(52.9 \%$ vs $87.9 \%)$ and more likely to receive only medical $(30.9 \%$ vs $11.6 \%)$ or endovascular $(16.2 \%$ vs $0.5 \%)$ management $(P<.001)$. Overall in-hospital mortality was $63.2 \%$ and $23.8 \%$ in patients with and without mesenteric malperfusion, respectively $(P<.001)$. In-hospital mortality of patients with mesenteric malperfusion receiving medical, endovascular, and surgical/hybrid therapy was $95.2 \%, 72.7 \%$, and $41.7 \%$, respectively $(P<.001)$. At multivariate analysis, male gender (odds ratio [OR], $1.7 ; P=.002$ ), age (OR, 1.1/y; $P=.002)$, and renal failure (OR, $5.9 ; P=.020)$ were predictors of mortality whereas surgical/hybrid management $(\mathrm{OR}, 0.1 ; P=.005)$ was associated with better outcome.

Conclusions: Type A acute aortic dissection complicated by mesenteric malperfusion is a rare but ominous complication carrying a high risk of hospital mortality. Surgical/hybrid therapy, although associated with 2 -fold hospital mortality, appears to be associated with better long-term outcomes in the management of type A acute aortic dissection in this setting. (J Thorac Cardiovasc Surg 2013;145:385-90)

From the Cardiovascular Surgery Department, ${ }^{\mathrm{a}}$ Sant'Orsola-Malpighi Hospital, Bologna University, Bologna, Italy; the Cardiovascular Centre "E. Malan,"b IRCCS Policlinico San Donato, San Donato, Italy; the Cardiac Surgery Department, ${ }^{\mathrm{c}}$ University of Michigan, Ann Arbor, Mich; the Department of Cardiology, ${ }^{\mathrm{d}}$ University of Calgary Medical Centre, Calgary, Alberta, Canada; Cardiovascular Medicine, ${ }^{\mathrm{e}}$ University of Tokyo, Tokyo, Japan; the Division of Cardiac Surgery, ${ }^{\mathrm{f}}$ St Michael's Hospital, Toronto, Ontario, Canada; the Division of Medical Genetics, ${ }^{\mathrm{g}}$ University of Pennsylvania School of Medicine, Philadelphia, Pa; the Cardiovascular Division, ${ }^{\text {h }}$ Washington University School of Medicine, St Louis, Mo; the Cardiology Department, ${ }^{i}$ University of Michigan, Ann Arbor, Mich; the Thoracic Aortic Center, ${ }^{\mathrm{j}}$ Massachusetts General Hospital, Boston, Mass; and the Department of Internal Medicine, ${ }^{\mathrm{k}}$ University Hospital Eppendorf-Rostock, Rostock, Germany. Disclosures: Authors have nothing to disclose with regard to commercial support.

Received for publication Sept 16, 2011; revisions received Nov 28, 2011; accepted for publication Jan 16, 2012; available ahead of print Feb 17, 2012.

Address for reprints: Marco Di Eusanio, MD, PhD, Cardiac Surgery Department; Pad 25. Policlinico Sant'Orsola-Malpighi; Università di Bologna, Via Massarenti 9, 40128, Bologna, Italy (E-mail: marco.dieusanio2@unibo.it).

$0022-5223 / \$ 36.00$

Copyright (C) 2013 by The American Association for Thoracic Surgery

doi:10.1016/j.jtcvs.2012.01.042
Supplemental material is available online.

Over the past 2 decades, knowledge of natural history, diagnosis, and management of acute type A aortic dissection has markedly improved. Despite this, hospital mortality in patients with aortic dissection remains substantial, ranging from $7 \%$ to $30 \% .^{1-3}$ Preoperative patients' characteristics mostly affect hospital outcomes, with the worst results being reported in patients with hypotension, tamponade, and organ malperfusion. ${ }^{4}$

Although several studies have assessed outcomes of patients with type A aortic dissection complicated by endorgan malperfusion syndromes, few have focused on mesenteric malperfusion. The International Registry of Acute Dissection (IRAD) represents a unique opportunity to study a large group of patients with aortic dissection collected in 18 referral centers worldwide. 


$$
\begin{aligned}
& \text { Abbreviations and Acronyms } \\
& \begin{aligned}
\mathrm{CI}= & \text { confidence interval } \\
\mathrm{IRAD}= & \text { International Registry of Acute } \\
& \text { Dissection } \\
\mathrm{NS}= & \text { not significant } \\
\mathrm{OR}= & \text { odds ratio }
\end{aligned}
\end{aligned}
$$

Aims of the present study were to compare clinical/imaging characteristics, management, and outcome of patients with type A acute dissection with and without mesenteric malperfusion and to assess outcomes of patients with mesenteric malperfusion according to different therapeutic strategies (surgical/hybrid, endovascular, and exclusively medical).

\section{METHODS}

\section{Study Population and Data Collection}

The rationale and methodology of IRAD have been published previously. ${ }^{5,6}$ At the time of our study, we examined 1809 consecutive patients with type A acute dissection enrolled at 18 institutions between December 1995 and August 2010. Acute type A dissection was defined as any dissection that involved the ascending aorta and/or aortic arch appearing within 14 days of the onset of symptoms. The diagnosis of aortic dissection was based on history, imaging studies, direct visualization at surgery, and/or postmortem findings. Patients were categorized according to presence/absence of mesenteric malperfusion, which was defined as any radiologic evidence of decreased perfusion through the celiac trunk, superior mesenteric artery, and inferior mesenteric artery with decreased viability or necrosis of the gut, with or without lactic acidosis, pain, or abdominal distention.

All patients were classified according to 3 different therapeutic strategies: surgical/hybrid, endovascular, and exclusively medical therapy. A surgical/ hybrid procedure was defined as a planned central aortic operation (ascending aorta/arch replacement) possibly associated with any percutaneous aortic or branch artery procedure (fenestration, stenting) performed simultaneously or within the same hospitalization. Endovascular treatment was defined as any percutaneous aortic or branch artery procedure (fenestration, stenting) in which any other central surgical procedure was not performed.

IRAD data forms were used to collect 290 clinical variables, including patient demographics, history, clinical presentation, physical findings, imaging studies, therapeutic management, in-hospital mortality, and adverse events. Completed data forms were forwarded to the coordinating center at the University of Michigan and reviewed for faced validity and completeness.

\section{Statistical Analysis}

Continuous variables were expressed as the mean \pm 1 standard deviation or median and Q1-Q3 and categorical variables as percentages. In all cases, missing data were not defaulted to negative, and denominators reflect only cases reported.

Univariate analyses between groups were done using $\chi^{2}$ tests (or Fisher exact tests) and Student $t$ tests where appropriate. All $P$ values are 2 -sided.

Preoperative and intraoperative variables were first analyzed using univariate analysis to determine whether any single factor was related to therapeutic strategy and hospital mortality in all patients and in those with mesenteric malperfusion. Variables that achieved $P$ values less than .15 in the univariate analysis were examined using gender-adjusted multivariate analysis by forward stepwise logistic regression to estimate the independent odds ratios (ORs) of factors related to nonsurgical/hybrid management (all patients and patients with mesenteric malperfusion) and hospital mortality in patients with mesenteric malperfusion.
Statistical analysis was performed by SPSS version 18.0 (SPSS, Inc, Chicago, Ill).

\section{RESULTS}

\section{Clinical Characteristics of Patients With and Without Mesenteric Malperfusion (Tables 1, 2, and 3)}

Of 3099 consecutive patients with acute aortic dissection enrolled between December 1995 and August 2010, 1967 $(63.5 \%)$ had type A dissection. Sixty-eight $(3.8 \%)$ of 1809 patients with available data had mesenteric malperfusion.

Compared with those who did not have mesenteric malperfusion, those who did were older $(61.8 \pm 14.4$ vs 57.9 \pm 14.4 years; $P=.028$ ) and more likely to have abdominal $(58.5 \%$ vs $24.2 \% ; P<.001)$, leg $(35.9 \%$ vs $12.0 \%$; $P<.001)$, and migrating $(21.3 \%$ vs $12.1 \% ; P=.032)$ pain. Patients with mesenteric malperfusion more frequently had coma $(10.0 \%$ vs $3.1 \% ; P=.003)$, ischemic spinal cord damage $(6.8 \%$ vs $0.8 \% ; P=.002)$, acute renal failure $(52.2 \%$ vs $7.2 \% ; P<.001)$, limb ischemia $(38.5 \%$ vs $9.9 \% ; P<.001)$, and any pulse deficit $(45.8 \%$ vs $29.8 \% ; P=.009)$.

Electrocardiographic evidence of new myocardial infarction $(8.5 \%$ vs $7.2 \% ; P=$ not significant $[\mathrm{NS}])$, left ventricular hypertrophy $(24.1 \%$ vs $20.9 \% ; P=\mathrm{NS})$, and low voltage $(5.2 \%$ vs $4.5 \% ; P=\mathrm{NS})$ were similar in patients with and without mesenteric malperfusion. On imaging studies, widened mediastinum $(52.0 \%$ vs $54.1 \%$; $P=\mathrm{NS})$, pleural effusion $(20.8 \%$ vs $12.4 \% ; P=\mathrm{NS})$, aortic regurgitation $(65.5 \%$ vs $53.5 \% ; P=\mathrm{NS})$, and coronary artery compromise $(16.7 \%$ vs $12.4 \% ; P=\mathrm{NS})$ were equally present in patients with and without mesenteric malperfusion.

Computed tomographic angiography, magnetic resonance imaging, and transesophageal echocardiography were used with similar frequency to assess characteristics of dissection in patients with and without mesenteric malperfusion. Angiography was more frequently performed in patients with mesenteric malperfusion $(33.3 \%$ vs $11.0 \%$; $P<.001$ ), in whom an overall higher number of imaging tests were required to complete the diagnostic process $(2.0 \pm 0.8$ vs $1.6 \pm 0.6 ; P<.001)$. Despite that, the time delay (hours) between symptom onset and diagnosis was similar in patients with and without mesenteric malperfusion (6.5 vs $5.8 ; P=\mathrm{NS})$.

The intimal-medial flap originated more frequently at the aortic root $(62.7 \%$ vs $45.2 \% ; P=.005)$ in patients with mesenteric malperfusion and at the ascending aorta $(36.5 \%$ vs $23.9 \% ; P=.035)$ in patients without mesenteric malperfusion. Patients with mesenteric malperfusion were more likely to have arch vessel involvement $(52.9 \%$ vs $35.7 \% ; P=.012)$ and any renal artery $(70.6 \%$ vs $18.0 \% ; P<.001)$ involvement by the dissection. 
TABLE 1. Demographics and history of patients with and without mesenteric malperfusion

\begin{tabular}{|c|c|c|c|}
\hline Variable & Mesenteric malperfusion $(n=68)$ & No mesenteric malperfusion $(n=1741)$ & $P$ value \\
\hline Age, mean $( \pm \mathrm{SD})$, y & $61.8 \pm 14.4$ & $57.9 \pm 14.4$ & .028 \\
\hline Male $(\%)$ & $47 / 68(69.1)$ & $1171 / 1741(67.3)$ & .749 \\
\hline White $(\%)$ & $54 / 62(87.1)$ & $1461 / 1629(89.7)$ & .512 \\
\hline Atherosclerosis $(\%)$ & $16 / 66(24.2)$ & $377 / 1676(22.5)$ & .739 \\
\hline Diabetes $(\%)$ & $3 / 66(4.5)$ & $96 / 1669(5.8)$ & .796 \\
\hline Hypertension $(\%)$ & $47 / 66(71.2)$ & $1208 / 1693(71.4)$ & .980 \\
\hline Aortic valve disease $(\mathrm{AS}+\mathrm{AR})(\%)$ & $8 / 65(12.3)$ & $63 / 1672(12.1)$ & .956 \\
\hline Bicuspid aortic valve $(\%)$ & $3 / 53(5.7)$ & $202 / 1669(12.1)$ & .668 \\
\hline Marfan $(\%)$ & $2 / 66(3.0)$ & $74 / 1687(4.4)$ & .767 \\
\hline Peripartum $(\%)$ & - & $4 / 1653(0.2)$ & 1.000 \\
\hline Cocaine abuse $(\%)$ & - & $19 / 1656(1.1)$ & .643 \\
\hline Known aortic aneurysm $(\%)$ & $5 / 66(7.6)$ & $210 / 1683(12.5)$ & .260 \\
\hline Prior aortic dissection $(\%)$ & - & $72 / 1684(4.3)$ & .110 \\
\hline Iatrogenic dissection $(\%)$ & $2 / 65(3.1)$ & $55 / 1665(3.3)$ & 1.000 \\
\hline Prior cardiac surgery $(\%)$ & $15 / 65(23.1)$ & $245 / 1660(14.8)$ & .066 \\
\hline History of catheterization/angiography & $9 / 53(17.0)$ & $155 / 1390(11.2)$ & .189 \\
\hline
\end{tabular}

$S D$, Standard deviation; $A S$, aortic stenosis; $A R$, aortic regurgitation.

\section{Therapeutic Strategies for Patients With and Without Mesenteric Malperfusion}

All patients. Overall, 86.7\% (1567 of 1809) of patients with acute type A dissection underwent surgical/hybrid procedures and 1.0\% (19 of 1809) and 12.3\% (223 of $1809)$ received endovascular and medical management, respectively.

On binary logistic regression, preoperative mesenteric malperfusion (OR, 7.9; 95\% confidence interval [CI], $3.229-19.521 ; P<.001)$, age more than 70 years $(\mathrm{OR}$, $2.9 ; 95 \% \mathrm{CI}, 1.782-4.884 ; P<.001)$, and female gender (OR, 2.1; 95\% CI, 1.317-3.557; $P=.002$ ) were the strongest independent predictors of receiving medical/endovascular management.

Patients with and without mesenteric malperfusion (Table 4). Patients with mesenteric malperfusion were less likely to undergo surgical/hybrid treatment $(52.9 \%$ vs $87.9 \% ; P<.001)$ and more likely to receive medical $(30.9 \%$ vs $11.6 \% ; P<.001)$ or endovascular $(16.2 \%$ vs $0.5 \% ; P<.001)$ management, when compared with patients without mesenteric malperfusion.

In surgically managed patients, the extent of aortic replacement, rate of associated cardiac procedures $(8.6 \% \mathrm{vs}$ $12.6 \% ; P=\mathrm{NS})$, and rate of open aortic anastomosis $(84.0 \%$ vs $94.1 \% ; P=\mathrm{NS})$ were equally distributed in patients with and without mesenteric malperfusion. Patients with mesenteric malperfusion were more likely to require an associated peripheral vascular surgical procedure $(11.1 \%$ vs $3.5 \% ; P=.018)$ (Table E1).

Patients with mesenteric malperfusion. Preoperatively, clinical and dissection imaging features were similar in patients receiving surgical/hybrid, endovascular, or medical treatment, except for older age being more frequent in patients receiving medical management (medical vs surgical/hybrid: $65.0 \pm 15.9$ vs $54.1 \pm 13.1$ years; $P=.007$; medical vs endovascular: $65.0 \pm 15.9$ vs 56.6 \pm 11.1 years; $P=\mathrm{NS}$; surgical/hybrid vs endovascular: $54.1 \pm 13.1$ vs $56.6 \pm 11.1$ years; $P=$ NS). Severe comorbid illness was reported as a contraindication to surgical repair in all cases and, on logistic regression, age greater than 70 years (OR, 5.2; 95\% CI, 0.741-36.526; $P=.097$ ) emerged as the only independent predictor of medical/endovascular management.

\section{Hospital Results}

Patients with and without mesenteric malperfusion (Table 5). Hospital mortality was $63.2 \%$ (43 of 68) and $23.8 \%$ (414 of 1741) in patients with and without mesenteric malperfusion, respectively $(P<.001)$.

On multiple logistic regression, mesenteric malperfusion (OR, 2.520; 95\% CI, 1.127-5.633), age greater than 70 years (OR, 2.327; 95\% CI, 1.680-3.222), migrating pain (OR, 1.747; 95\% CI, 1.126-2.710), hypotension/shock/ tamponade (OR, 2.636; 95\% CI, 1.915-3.629), renal failure (OR, 2.076; 95\% CI, 1.466-2.940), and abnormal electrocardiogram (OR, 1.568; 95\% CI, 1.113-2.210) emerged as independent predictors of in-hospital mortality.

Postoperative occurrence of new major brain injuries (stroke or coma), myocardial ischemic complications, and cardiac tamponade were equally observed in patients with and without mesenteric malperfusion. Patients with mesenteric malperfusion were more likely to have postoperative renal failure $(44.4 \%$ vs $16.8 \% ; P<.001)$ and limb ischemia $(9.6 \%$ vs $3.1 \% ; P=.009)$.

Patients with mesenteric malperfusion. In patients with mesenteric malperfusion, hospital mortality was $95.2 \%$ (20 of 21) after medical management, $72.7 \%$ (8 of 11 ) after endovascular treatment, and $41.7 \%$ (15 of 36$)$ after 
TABLE 2. Clinical presentation of patients with and without mesenteric malperfusion

\begin{tabular}{|c|c|c|c|}
\hline Variable & $\begin{array}{l}\text { Mesenteric malperfusion } \\
\qquad(\mathrm{n}=68)\end{array}$ & $\begin{array}{c}\text { No mesenteric } \\
\text { malperfusion }(n=1741)\end{array}$ & $P$ value \\
\hline Time from symptom onset to diagnosis (h) & $6.5(1.3-23.8)$ & $5.8(1.9-24.0)$ & .325 \\
\hline Time from diagnosis to surgical/hybrid or endovascular treatment (h) & $9.0(2.3-24.0)$ & $4.8(2.1-18.1)$ & .193 \\
\hline Time from symptom onset to surgical/hybrid or endovascular treatment (h) & $19.1(8.8-65.0)$ & $14.8(6.8-40.5)$ & .743 \\
\hline Chest pain $(\%)$ & $48 / 68(70.6 \%)$ & $1348 / 1672(80.6 \%)$ & .042 \\
\hline Anterior $(\%)$ & $43 / 55(78.2)$ & 1075/1378 (78.0) & .976 \\
\hline Posterior $(\%)$ & $15 / 44(34.1)$ & $487 / 1274(38.2)$ & .579 \\
\hline Back pain $(\%)$ & $32 / 66(48.5)$ & 682/1622 (42.0) & 299 \\
\hline Abdominal pain $(\%)$ & $38 / 65(58.5)$ & $389 / 1610(24.2)$ & $<.001$ \\
\hline Leg pain $(\%)$ & 23/64 (35.9) & $191 / 1593(12.0)$ & $<.001$ \\
\hline \multicolumn{4}{|l|}{ Quality of pain } \\
\hline Migrating (\%) & $13 / 61(21.3)$ & $189 / 1563(12.1)$ & .032 \\
\hline Radiating (\%) & $24 / 63(38.1)$ & $560 / 1583(35.4)$ & .658 \\
\hline \multicolumn{4}{|l|}{ Pain severity $(\%)$} \\
\hline Mild (\%) & - & $117 / 1350(8.7)$ & .304 \\
\hline Severe $(\%)$ & $40 / 52(76.9)$ & $1008 / 1350(74.7)$ & .713 \\
\hline Worst ever $(\%)$ & $12 / 52(23.1)$ & 225/1350 (16.7) & .226 \\
\hline Abrupt onset of pain $(\%)$ & $59 / 65(90.8)$ & $1335 / 1619(82.5)$ & .082 \\
\hline Febrile & $4 / 54(7.4)$ & $34 / 1319(2.6)$ & .059 \\
\hline Hypotension/shock/tamponade (\%) & $18 / 64(28.1)$ & $449 / 1628(27.6)$ & .924 \\
\hline Hypertension $(\%)$ & $22 / 64(34.4)$ & 493/1628 (30.3) & .485 \\
\hline Syncope $(\%)$ & 8/67 (11.9) & 297/1644 (18.1) & .199 \\
\hline Cerebrovascular accident $(\%)$ & $6 / 63(9.5)$ & $84 / 1624(5.2)$ & .132 \\
\hline Coma $(\%)$ & 6/60 (10.0) & $50 / 1626(3.1)$ & .003 \\
\hline Ischemic spinal cord damage $(\%)$ & $4 / 59(6.8)$ & $13 / 1628(0.8)$ & .002 \\
\hline Myocardial ischemia/infarction (\%) & $12 / 66(18.2)$ & 193/1733 (11.1) & .077 \\
\hline Cardiac heart failure $(\%)$ & $9 / 63(14.3)$ & $127 / 1670(7.6)$ & .053 \\
\hline Acute renal failure $(\%)$ & $35 / 67(52.2)$ & $124 / 1729(7.2)$ & $<.001$ \\
\hline Limb ischemia $(\%)$ & $25 / 65(38.5)$ & $171 / 1728(9.9)$ & $<.001$ \\
\hline Any pulse deficit $(\%)$ & $27 / 59(45.8)$ & $394 / 1321(29.8)$ & .009 \\
\hline
\end{tabular}

surgical/hybrid treatment $(P<.001)$. In the 43 patients with mesenteric malperfusion who died, causes of death were visceral ischemia $(n=15 ; 34.9 \%)$, neurologic $(n=2 ; 7.0 \%)$, multiorgan failure $(\mathrm{n}=5 ; 11.6 \%)$, cardiac $(\mathrm{n}=2 ; 4.7 \%)$, tamponade $(\mathrm{n}=2 ; 4.7 \%)$, and not specified $(\mathrm{n}=15 ; 44.9 \%)$.

At binary logistic regression, surgical/hybrid management (OR, 0.1; 95\% CI, 0.028-0.539; $P=.005$ ) resulted as a protective factor for hospital mortality, whereas male gender (OR, 1.7; 95\% CI, 0-338-7.397; $P=.484)$, age (OR, 1.112; 95\% CI, 1.041-1.188; $P=.002$ ), and preoperative renal failure (OR, 5.989; 95\% CI, 1.328-26.182; $P=.020)$ were associated with increased hospital mortality.

\section{DISCUSSION}

Aortic dissection remains one of the most lethal cardiovascular diseases, and end-organ malperfusion syndromes, which occur in approximately in one-third of patients, ${ }^{4}$ are associated with elevated mortality and dismal postoperative outcomes. $^{7-9}$

Among different ischemic end-organ complications occurring at the onset of dissection, mesenteric malperfusion is one of the most insidious and therefore challenging for diagnostic and management decision making. ${ }^{10}$
Our data show that mesenteric malperfusion is a rare complication of acute dissection and that, very commonly, is associated with clinical or imaging signs of other organ injury or malperfusion. In our series of 1809 patients with type A acute dissection, only $68(3.8 \%)$ met our definition of mesenteric malperfusion and approximately $30 \%$ of them showed clinical symptoms or signs of neurologic complications, $52.2 \%$ had acute renal failure, and $30 \%$ had limb ischemia. Although the mentioned associated complications may not involve malperfusion as the only underlying pathogenetic mechanism, imaging data, showing extremely high rates of arch vessel $(52.9 \%)$ and any renal artery involvement $(70.6 \%)$ by the dissection, support the idea that malperfusion plays an important role and that, when it occurs, it is likely to involve more than one vascular territory. Interestingly, the observation that about $40 \%$ of patients with mesenteric ischemia did not have abdominal pain, whereas about $20 \%$ of patients without mesenteric malperfusion had pain, confirms that abdominal pain is a nonspecific symptom of acute mesenteric ischemia. ${ }^{11,12}$ Moreover, the typically progressive nature of both the aortic dissecting disease and malperfusive complication, in addition to the potential different times of patients' presentation with different degrees of bowel ischemia, may 
TABLE 3. Characteristics of dissection in patients with and without mesenteric malperfusion

\begin{tabular}{|c|c|c|c|}
\hline Variable & Mesenteric malperfusion $(n=68)$ & No mesenteric malperfusion $(n=1741)$ & $P$ value \\
\hline \multicolumn{4}{|l|}{ Origin of dissection flap } \\
\hline Sinotubular junction $(\%)$ & $5 / 67(7.5)$ & $195 / 1628(12.0)$ & .262 \\
\hline Aortic root $(\%)$ & $42 / 67(62.7)$ & $736 / 1628(45.2)$ & .005 \\
\hline Ascending $(\%)$ & $16 / 67(23.9)$ & $594 / 1628(36.5)$ & .035 \\
\hline $\operatorname{Arch}(\%)$ & $3 / 67(4.5)$ & $66 / 1628(4.1)$ & .863 \\
\hline \multicolumn{4}{|l|}{ False lumen patency } \\
\hline Patent $(\%)$ & $38 / 50(76.0)$ & $753 / 1063(70.8)$ & .431 \\
\hline Partial thrombosis $(\%)$ & $10 / 50(20.0)$ & 208/1063 (19.6) & .940 \\
\hline Complete thrombosis $(\%)$ & $2 / 50(4.0)$ & $102 / 1063(9.6)$ & .184 \\
\hline Distal communication $(\%)$ & $17 / 44(38.6)$ & 243/1015 (23.9) & .027 \\
\hline Arch vessel involvement $(\%)$ & $27 / 51(52.9)$ & $429 / 1203(35.7)$ & .012 \\
\hline Any renal artery involvement $(\%)$ & $48 / 68(70.6)$ & $309 / 1716(18.0)$ & $<.001$ \\
\hline Coronary arteries compromised (\%) & $8 / 48(16.7)$ & $156 / 1262(12.4)$ & .376 \\
\hline Aortic regurgitation $(\%)$ & $36 / 55(65.5)$ & $773 / 1445(53.5)$ & .081 \\
\hline \multicolumn{4}{|l|}{ Aortic measurements } \\
\hline Aortic annulus $(\mathrm{cm})$ & $2.6(2.3-2.9)$ & $2.5(2.3-2.9)$ & .878 \\
\hline Aortic root $(\mathrm{cm})$ & $4.5(3.8-5.9)$ & $4.2(3.7-5.0)$ & .511 \\
\hline Ascending aorta (widest) $(\mathrm{cm})$ & $4.9(4.5-5.5)$ & $5.0(4.4-5.8)$ & .539 \\
\hline Aortic $\operatorname{arch}(\mathrm{cm})$ & $4.0(3.5-4.4)$ & $3.6(3.2-4.1)$ & .252 \\
\hline Descending aorta (widest) $(\mathrm{cm})$ & $3.3(3.0-4.2)$ & $3.4(3.0-3.8)$ & .875 \\
\hline
\end{tabular}

justify our rate of patients without abdominal pain of $40 \%$, which is slightly superior to the $25 \%$ reported in literature. ${ }^{12}$

In IRAD, patients with mesenteric malperfusion were less likely to undergo surgical treatment and more likely to receive a recognized suboptimal therapeutic management, namely, medical or endovascular therapy. Moreover, such a difference in therapeutic management was striking: about $50 \%$ of patients with mesenteric malperfusion did not receive surgical therapy against $12 \%$ of patients without. Accordingly, binary logistic regression confirmed these observations by indicating mesenteric malperfusion as the strongest predictor of medical therapy in the overall series (OR, 7.9).

These data clearly reflect surgeons' attitudes to avoid surgery in patients with severe preoperative comorbidities and indicate that mesenteric malperfusion, among all preoperative dissection-related complications, is considered as (one of) the most threatening.

Almost two-thirds of patients with mesenteric malperfusion died during hospitalization, almost 3 times the number of those patients without the mentioned complication $(63.2 \%$ vs $23.8 \%)$.
However, when assessing hospital mortality according to different therapeutic management, in patients with mesenteric malperfusion an interesting scenario becomes evident: medical and endovascular therapies were associated with dismal mortality rates $(95.2 \%$ and $72.7 \%$, respectively), whereas surgical/hybrid therapy was associated with a significantly higher survival of $41.7 \%$.

Accordingly, our binary logistic regression indicated that surgical/hybrid therapy for patients deemed operable by the treating facility was associated with the best survival in patients with mesenteric malperfusion, even after adjusting for gender, age, and renal failure. This is likely due to both patient selection and the potential benefit of definitive repair.

When surgical treatment is used, operative timing and potential use of percutaneous procedures (fenestration/ stenting) to address branch artery obstruction still represent greatly debated issues.

Some authors, ${ }^{13,14}$ given the unpredictable nature of acute type A dissection and its ever-present potential for rupture, advocate immediate correction of malperfusion syndromes by replacing the ascending and/or transverse aortic arch, thus

TABLE 4. Therapeutic strategies for patients with and without mesenteric malperfusion

\begin{tabular}{|c|c|c|c|}
\hline Therapeutic strategies & Mesenteric malperfusion $(n=68)$ & No mesenteric malperfusion $(n=1741)$ & $P$ value \\
\hline Surgical/Hybrid (\%) & $36 / 68(52.9)$ & $1531 / 1741(87.9)$ & $<.001$ \\
\hline Open surgery + aortic fenestration $(\%)$ & $0 / 4(0.0)$ & $1 / 14(7.1)$ & 1.000 \\
\hline Open surgery + aortic stenting $(\%)$ & $2 / 4(50.0)$ & $12 / 14(85.7)$ & .197 \\
\hline Open surgery + aortic stenting and fenestration & $2 / 4(50.0)$ & $1 / 14(7.1)$ & .108 \\
\hline Endovascular (\%) & $11 / 68(16.2)$ & $8 / 1741(0.5)$ & $<.001$ \\
\hline Aortic fenestration $(\%)$ & 2/11 (18.2) & $2 / 8(25.0)$ & 1.000 \\
\hline Aortic stenting $(\%)$ & 2/11 (18.2) & $2 / 8(25.0)$ & 1.000 \\
\hline Aortic stenting and fenestration $(\%)$ & $7 / 11(63.6)$ & $4 / 8(50.0)$ & .658 \\
\hline Exclusively medical (\%) & 21/68 (30.9) & 202/1741 (11.6) & $<.001$ \\
\hline
\end{tabular}


TABLE 5. In-hospital mortality and complications for patients with type A acute dissection with and without mesenteric malperfusion

\begin{tabular}{lccc}
\hline & Mesenteric malperfusion $(\mathbf{n}=\mathbf{6 8})$ & No mesenteric malperfusion $(\mathbf{n}=\mathbf{1 7 4 1})$ & $\boldsymbol{P}$ value \\
\hline Mortality (\%) & $43 / 68(63.2)$ & $414 / 1741(23.8)$ & $<.001$ \\
Major brain injury (coma +stroke) (\%) & $5 / 42(11.9)$ & $129 / 1532(8.4)$ & .575 \\
Spinal cord injury (\%) & $1 / 45(2.2)$ & $13 / 1551(0.8)$ & .331 \\
Myocardial infarction/ischemia (\%) & $4 / 59(6.8)$ & $96 / 1689(5.7)$ & .772 \\
Acute renal failure (\%) & $20 / 45(44.4)$ & $286 / 1701(16.8)$ & $<.001$ \\
Limb ischemia (\%) & $5 / 52(9.6)$ & $52 / 1695(3.1)$ & .025 \\
Cardiac tamponade (\%) & $5 / 57(8.8)$ & $91 / 1659(5.5)$ & .370 \\
\hline
\end{tabular}

restoring blood flow into the true lumen. Others, ${ }^{9,10,15-17}$ in selected patients showing clinical deterioration owing to established end-organ ischemic dysfunction, suggest alternative management strategies such as delayed central aortic operation after percutaneous end-organ blood flow restoration. This approach, which certainly takes into account the potential for aortic rupture before ascending aortic repair has been accomplished, finds its rationale in the predominant prognostic weight of the end-organ dysfunction and in the suboptimal surgical outcomes reported in this setting.

Our analysis does not allow us to distinguish the best therapeutic option between the aforementioned approaches. However, IRAD data show that hybrid management (central aortic operation plus percutaneous treatment of mesenteric malperfusion) was applied in only a very few cases and that immediate surgical repair of the proximal dissected aorta still represents the most common therapeutic approach for patients with type A acute dissection complicated by mesenteric malperfusion.

\section{Limitations and Strengths}

Our definition of mesenteric malperfusion does not allow distinguishing patients with different degrees of intestinal ischemic injury As a consequence, differences in clinical features, management, and outcomes of patients according to the presence/absence of intestinal infarction could not be captured, and the comparison between surgical/hybrid, endovascular, and medical management might have been influenced by a selection bias in the therapeutic referral process.

Data on intestinal surgical procedures are not available in the IRAD registry. Thus, the clinical relevance and prognostic implications of concomitant abdominal surgery could not be evaluated.

Current knowledge about mesenteric malperfusion is based on case studies with an extremely limited number of patients, or extrapolated by larger reports including different organ malperfusion syndromes. Our study, analyzing the largest series of patients with mesenteric malperfusion, may help shed light on this high-risk group of patients.

\section{CONCLUSIONS}

Our data showed that patients with mesenteric malperfusion are older and frequently have associated neurologic, renal, and limb dissection-related complications. Mesenteric malperfusion is a rare but ominous complication carrying a 3-fold higher risk of hospital mortality. When compared with different therapeutic treatments, surgical/hybrid therapy appears to be associated with better outcomes.

\section{References}

1. Fann JI, Smith JA, Miller DC, Mitchell RS, Moore KA, Grunkemeier G, et al. Surgical management of aortic dissection during a 30-year period. Circulation. 1995;92(9 Suppl):II113-21.

2. Ehrlich M, Fang WC, Grabenwöger M, Cartes-Zumelzu F, Wolner E, Havel M. Perioperative risk factors for mortality in patients with acute type A aortic dissection. Circulation. 1998;98(19 Suppl):II294-8.

3. Miller DC, Mitchell RS, Oyer PE, Stinson EB, Jamieson SW, Shumway NE. Independent determinants of operative mortality for patients with aortic dissections. Circulation. 1984;70(3 Pt 2):I153-64.

4. Trimarchi S, Nienaber CA, Rampoldi V, Myrmel T, Suzuki T, Mehta RH, et al., Investigators IRAD. Contemporary results of surgery in acute type A aortic dissection: the International Registry of Acute Aortic Dissection experience. J Thorac Cardiovasc Surg. 2005;129:112-22.

5. Hagan PG, Nienaber CA, Isselbacher EM, Bruckman D, Karavite DJ, Russman PL, et al. The International Registry of Acute Aortic Dissection (IRAD): new insights into an old disease. JAMA. 2000;283:897-903.

6. Tsai TT, Trimarchi S, Nienaber CA. Acute aortic dissection: perspectives from the International Registry of Acute Aortic Dissection (IRAD). Eur J Vasc Endovasc Surg. 2009;37:149-59.

7. Okita Y, Takamoto S, Ando M, Morota T, Kawashima Y. Surgical strategies in managing organ malperfusion as a complication of aortic dissection. Eur J Cardiothorac Surg. 1995;9:242-6; discussion 247.

8. Girardi LN, Krieger KH, Lee LY, Mack CA, Tortolani AJ, Isom OW. Management strategies for type A dissection complicated by peripheral vascular malperfusion. Ann Thorac Surg. 2004;77:1309-14; discussion 1314.

9. Girdauskas E, Kuntze T, Borger MA, Falk V, Mohr FW. Surgical risk of preoperative malperfusion in acute type A aortic dissection. J Thorac Cardiovasc Surg. 2009; 138:1363-9.

10. Deeb GM, Patel HJ, Williams DM. Treatment for malperfusion syndrome in acute type $\mathrm{A}$ and $\mathrm{B}$ aortic dissection: a long-term analysis. J Thorac Cardiovasc Surg. 2010;140:S98-100; discussion S142-6.

11. Wasnik A, Kaza RK, Al-Hawary MM, Liu PS, Platt JF. Multidetector CT imaging in mesenteric ischemia-pearls and pitfalls. Emerg Radiol. 2011;18:145-56.

12. Howard TJ, Plaskon LA, Wiebke EA, Wilcox MG, Madura JA. Nonocclusive mesenteric ischemia remains a diagnostic dilemma. Am J Surg. 1996;171:405-8.

13. Estrera AL, Huynh TTT, Porat EE, Miller CC, Smith JJ, Safi HJ. Is acute type A aortic dissection a true surgical emergency? Semin Vasc Surg. 2002;15:75-82.

14. Geirsson A, Szeto WY, Pochettino A, McGarvey ML, Keane MG, Woo YJ, et al. Significance of malperfusion syndromes prior to contemporary surgical repair for acute type A dissection: outcomes and need for additional revascularizations. Eur J Cardiothorac Surg. 2007;32:255-62.

15. Shiiya N, Matsuzaki K, Kunihara T, Murashita T, Matsui Y. Management of vital organ malperfusion in acute aortic dissection: proposal of a mechanism-specific approach. Gen Thorac Cardiovasc Surg. 2007;55:85-90.

16. Williams DM, Lee DY, Hamilton BH, Marx MV, Narasimham DL, Kazanjian SN, et al. The dissected aorta: percutaneous treatment of ischemic complications-principles and results. J Vasc Interv Radiol. 1997;8:605-25.

17. Di Luozzo G, Tannous HJ, Ellozy SH, Nowakowski S, Plestis KA, Adams DH, et al. Delayed repair of acute type A aortic dissection in a patient with gastrointestinal bleeding and pulse deficit. Ann Thorac Surg. 2007;84:2097-9. 
TABLE E1. Surgical procedures for patients with type A acute dissection with and without mesenteric malperfusion

\begin{tabular}{|c|c|c|c|}
\hline & Mesenteric malperfusion $(n=68)$ & No mesenteric malperfusion $(n=1741)$ & $P$ value \\
\hline \multicolumn{4}{|l|}{ Extent of aortic replacement } \\
\hline Root $(\%)$ & $10 / 30(33.3)$ & $482 / 1339(36.0)$ & .764 \\
\hline Ascending aorta $(\%)$ & 28/36 (77.8) & $1380 / 1483(93.1)$ & .001 \\
\hline Partial arch $(\%)$ & $10 / 37(27.0)$ & $564 / 1426(39.6)$ & .123 \\
\hline Complete arch $(\%)$ & $5 / 37(13.5)$ & $204 / 1435(14.2)$ & 1.000 \\
\hline Open procedure $(\%)$ & $21 / 25(84.0)$ & $866 / 920(94.1)$ & .061 \\
\hline \multicolumn{4}{|l|}{ Associated procedures $(\%)$} \\
\hline $\operatorname{AVR}(\%)$ & $8 / 34(23.5)$ & $394 / 1456(27.1)$ & .647 \\
\hline CABG $(\%)$ & $3 / 35(8.6)$ & $173 / 1446(12.0)$ & .791 \\
\hline MVR (\%) & - & $10 / 1449(0.7)$ & 1.000 \\
\hline Reoperation $(\%)$ & $5 / 34(14.7)$ & $189 / 1429(13.2)$ & .797 \\
\hline Peripheral vessels replaced & $4 / 36(11.1)$ & $51 / 1440(3.5)$ & .018 \\
\hline
\end{tabular}

